\title{
DESERTIFICAÇÃO NO NORDESTE: UMA APROXIMAÇÃO SOBRE O FENÔMENO DO RIO GRANDE NORTE
}

\author{
JESSICLEIDE DANTAS FERNANDES \\ Graduada em Administração. Especialista em Gestão e Perícia Ambiental - FARN \\ jessicleide@hotmail.com
}

ANNA JACINTA DANTAS DE MEDEIROS

Instituto Federal de Educação, Ciência e Tecnologia do Rio Grande do Norte, Campus Santa Cruz. Graduada em Tecnologia do Meio Ambiente e Farmácia.

Especialista em Saneamento Ambiental

anna.medeiros@cefetrn.br

\section{RESUMO}

A discussão das causas e conseqüências da desertificação, degradação de terras e ocorrência de secas é um assunto complexo e ainda tem sido pouco realizada. Nesse sentido, o presente trabalho se propõe a discutir sobre a desertificação, enquanto um processo socioambiental destruidor, e simultaneamente oferecer aos leitores informações reais sobre o semi-árido brasileiro, abordando alguns problemas ambientais, principalmente os da região do Seridó, que tem se destacado como um dos núcleos nacionais da desertificação. Para a realizada desse estudo, utilizou-se pesquisa bibliográfica e observação in loco, que contribuíram para que se elucidasse por meio das informações coletadas a realidade social de tal fenômeno, que através dos tempos tem transformado a região Nordeste em uma área vulnerável à contínua perda de produtividade da terra e da dignidade social e econômica de grande parte da sociedade local.

PALAVRAS-CHAVE: Desertificação, Sustentabilidade, Nordeste.

\begin{abstract}
The discussion on the causes and consequences of desertification, land degradation and drought events constitutes a complex subject which has not been widely debated. Considering that, this work aims to discuss desertification as a destructive environmental process, and simultaneously to offer real information about the Brazilian semi-arid, approaching some environmental problems, mainly in the Seridó region, that has stood out as one of the national desertification cores. This work was based on information collected through bibliographic research and observation in loco to elucidate the social reality of this phenomenon, which over time has transformed the Northeast in a vulnerable area, with the continuous loss of land productivity and social and economic dignity for much of the local society.
\end{abstract}

KEY-WORDS: Desertification, Sustainability, Northeast. 


\section{DESERTIFICAÇÃO NO NORDESTE: UMA APROXIMAÇÃO SOBRE O FENÔMENO DO RIO GRANDE NORTE}

\section{INTRODUÇÃO}

O Nordeste brasileiro, destacado como área atrasada e de miserabilidade, por apresentar elevados índices de analfabetismo e baixo índice de Desenvolvimento Humano (IDH), condicionou-se a ter uma imagem de região problema do Brasil. Essa região tem sua história marcada pelo colonialismo, o qual contribuiu para a reprodução e a acumulação do capital, resultando num processo seletivo e excludente do homem nordestino, que até hoje sofre com a falta de participação na vida política, social e econômica. Contudo, as riquezas naturais e o povo de cultura forte permitiram o desenvolvimento para a região dominada praticamente pelo bioma Caatinga, a qual comporta uma diversidade socioeconômica que está intrinsecamente ligada às questões antrópicas e adafoclimáticas.

Por possuir características que o torna limitante para algumas atividades agropastoris e um histórico de ações mitigadoras equivocadas, responsáveis por um desenvolvimento limitado, o Nordeste vem sofrendo sérios problemas de ordem ambiental. Um deles é a desertificação, um processo de empobrecimento dos recursos ambientais provocado por processos naturais e principalmente humanos. A Desertificação constitui um conjunto de processos que promovem o desequilíbrio dos meios físico, químico, biológico e socioeconômico, via de regra, desencadeados pela ação antrópica, que atua de forma conjunta com as limitações climáticas impostas a ambientes ecologicamente frágeis. Nesse sentido, passou a questionar em que medida esse processo tem afetado a vida do homem sertanejo e, em particular, do homem potiguar. Até que ponto o processo de desertificação constitui um fenômeno destruidor e gerador de problemas sociais e ambientais para o povo norte-rio-grandense? Essa é uma questão que será respondida ao longo deste estudo, que se propõe a discutir sobre esse processo ambiental seletivo e excludente.

A Agenda 21, o principal documento gerado pela Conferência Rio 1992, definiu desertificação como sendo a degradação da terra nas regiões áridas, semi-áridas, subáridas e sub-úmidas secas, resultantes de vários fatores, entre eles as variações climáticas e as atividades humanas. O fenômeno tem avançado em praticamente todas as áreas do semi-árido brasileiro. Isso tem feito com que áreas produtivas tornem-se verdadeiros “desertos", gerando problemas no campo da agricultura, pecuária, economia e limitando cada vez mais o desenvolvimento. A condição de semi-aridez não é fator determinante ao desenvolvimento de uma região. Porém, o que se tem visto na prática são ações de combate a um fenômeno natural que é a seca.

Dessa forma, torna-se necessária a utilização de tecnologias adequadas ao potencial produtivo da região juntamente com políticas de desenvolvimento, em que os elementos constituintes possam ser aproveitados de forma racional e sustentável. Assim, é de extrema importância rever velhos paradigmas e fantasmas que ainda evocam da sociedade a velha história de que a seca é um fenômeno que precisa de ações para ser combatida, pois, como é da sabedoria de todos, não se pode lutar contra fenômenos ou processos naturais, o mais prudente é adaptar-se à realidade ambiental e, a partir daí, promover um desenvolvimento com sustentabilidade através da capacidade de sustentação da Terra. 
A discussão das causas e conseqüências da desertificação, degradação de terras e ocorrência de secas é um assunto complexo e ainda pouco entendido. A relação entre desertificação e seca, por um lado, e a influência humana, de outro, ainda não foi completamente explicada. Secas ocasionais (devido à sazonalidade ou às variações inter-anuais das chuvas) e secas severas de longos períodos podem ser causadas ou agravadas pela influência humana sobre o meio ambiente (redução da cobertura vegetal, mudança do efeito de albedo etc). Assim, as atividades humanas contribuem para acelerar o processo de desertificação, agravando suas conseqüências negativas sobre as pessoas. (BRASIL, 2005, p.5).

É preciso buscar a harmonia entre os seres humanos e a natureza e criar, a partir desse princípio, a consciência de nosso dever com relação às gerações futuras e a limites que a natureza e o meio ambiente nos impõem, pois sustentabilidade "significa a possibilidade de se obterem continuamente condições iguais ou superiores de vida para um grupo de pessoas e seus sucessores em dado ecossistema” (CAVALCANTI, 2003, p. 165).

Uma caracterização consistente de sustentabilidade social deve basear-se nos valores primordiais de eqüidade e democracia, significando esta última a apropriação efetiva de todos os direitos humanos, políticos, civis, econômicos, sociais e culturais. (SACHS, 2006, p. 288). Sendo assim, o presente trabalho objetiva oferecer aos leitores informações reais sobre o semi-árido brasileiro, com destaque para o potiguar,no qual são abordados alguns problemas ambientais estaduais, principalmente os da região do Seridó, que tem se destacado como um dos núcleos nacionais da desertificação. Através de pesquisa bibliográfica, serão apresentadas informações sobre tal fenômeno que, através dos tempos, transformou a região Nordeste em uma área vulnerável à contínua perda de produtividade da terra, à exaustão de recursos naturais não-renováveis e à diminuição dos depósitos de água subterrânea.

O processo de desertificação em áreas mais sensíveis reflete as condições de uso insustentável dos solos, da vegetação, dos recursos hídricos e da biodiversidade. As atividades humanas e suas conseqüências sobre o uso do solo e da água são causa de grande pressão sobre esses recursos. (CAVALCANTI, 2003, p. 423).

\section{O NORDESTE BRASILEIRO E A CAATINGA}

O Nordeste brasileiro é uma região que apresenta características limitantes para o seu desenvolvimento, é ocupado quase que em sua totalidade por um tipo de ecossistema único no mundo - a Caatinga. De acordo com Branco (2004, p.7) o nome "caatinga” é de origem Tupi-Guarani e significa "floresta branca", o que caracteriza o aspecto do ecossistema durante o período de estiagem.

A caatinga brasileira estende-se de $2^{\circ} 54$ a $17^{\circ} 21^{\prime} \mathrm{S}$, ocupando aproximadamente uma área de $800.00 \mathrm{~km}^{2}$, representa $70 \%$ da região Nordeste e $11 \%$ do território nacional. Inclui os estados do Rio Grande do Norte, Ceará, Paraíba, Pernambuco, Sudeste do Piauí, Oeste de Alagoas e Sergipe, região Norte e Central da Bahia, uma faixa de Minas Gerais e parte de Fernando de Noronha. (TABARELLI, 2004, p.7).

Esse ecossistema possui características específicas, o que o torna único no mundo. O solo é sílico argiloso, seco, raso quase sem húmus, pedregoso, contendo regular teor de cálcio e potássio. Entre os aspectos meteorológicos, tem-se: a mais alta radiação solar, 
baixa nebulosidade, a mais alta temperatura média anual, as mais baixas taxas de umidade relativa, evapotranspiração potencial mais elevada e, principalmente, precipitações baixas e irregulares, limitando-se a um período de três meses consecutivos anuais, o que faz com que quase todos os rios da região se tornem intermitentes. Além disso, a região está sujeita a fenômenos catastróficos como secas e cheias, que interferem de forma decisiva na biota. Essa característica de semi-aridez é resultado principalmente da predominância de massas de ar estáveis empurradas para o sudeste pelos ventos alísios.

Quanto à temperatura, as médias absolutas máximas são raramente superiores a $40^{\circ} \mathrm{C}$, porém existem variações de acordo com a altitude, a exemplo de áreas superiores a $250 \mathrm{~m}$ de altitude com temperaturas mais brandas entre 20 a $22^{\circ} \mathrm{C}$, e precipitação média de 250 a $100 \mathrm{~mm}$ anuais.

A Biota da região devido a um precário conhecimento zoológico e botânico mostra que existe um equívoco a ser revisto. A falsa idéia de uma baixa biodiversidade até hoje perdura nas mais variadas bibliografias.

Trata-se do único ecossistema exclusivamente brasileiro, composto por um mosaico de florestas secas e vegetação arbustiva (savanaestépica), com enclaves de florestas úmidas, montanhas e cerrados. Até o momento foram registrados 932 espécies de plantas vasculares, 185 espécies de peixes, 154 répteis e anfíbios, 348 espécies de aves e 148 espécies de mamíferos, considerando as formações vegetais típicas da caatinga (MMA, 2000 apud TABARELLI, 2004, p. 737).

Com relação ao assunto, Guimarães Duque (1980, p.26) acrescenta que,

Na caatinga a associação florística com o solo e a atmosfera é quase uma simbiose, tal é o regime de economia rígida da água para entreter as funções em equilíbrio; a união densa, fechada, de caatingueiras, acácias, umbuzeiros, maniçobas, macambiras, cactáceas, pereiro, etc., protege o solo no inverno com a sua folhagem verde e no verão cobre-o com uma camada de folhas fenadas que são em parte comidas pelo gado e o restante aduba chão; as espécies, para sobreviverem em relativa harmonia fisiológica absorvem umidade do ar, com o abaixamento da temperatura à noite, quando a terra seca lhes nega água e forças ao repouso. Este é o seu clímax de estabilização vegetativa.

A flora - constituída principalmente de espécies lenhosas e herbáceas, de pequeno porte, e de cactáceas e bromeliáceas - para resistir às adversidades do meio ambiente teve que sofrer processos de adaptação de acordo com a sua anatomia. Assim, as principais adaptações encontradas são: folhas transformadas foliar, cobertura de cera, raízes axiais capazes de adentrarem no solo e retirar água de aluviões, reservas alimentícias armazenadas em raízes tuberculadas, nas batatas e xilopódios.

No que se refere à fauna, encontramos a maior diversidade de répteis e anfíbios. Além disso, é possível encontrar grande número de insetos adaptados ao clima seco com reprodução no inverno. Os mamíferos são de pequeno porte, sendo os roedores os mais 
abundantes. As espécies encontradas em maior número são aqueles que apresentam um comportamento migratório nos períodos de estiagem.

A caatinga tem sido bastante modificada pelo homem. Os seus bolos estão sofrendo um intenso processo de degradação devido à substituição da vegetação natural por culturas, nas quais normalmente são utilizadas práticas condenadas como as queimadas. Além disso, o desmatamento e as culturas irrigadas estão levando à salinização dos solos, o que tem como conseqüência um aumento da evaporação da água.

Dessa maneira como todo ecossistema global, a Caatinga precisa urgentemente de projeto para que o seu processo de degradação não continue a avançar da forma como está. Uma das saídas encontradas é a sua proteção através da criação das Áreas de Proteção Ambiental (APAs).

De acordo com Tabarelli (2004, p.778),

recentemente a Caatinga foi reconhecida como uma das 37 grandes regiões naturais do planeta. Grandes regiões naturais são ecossistemas que ainda abrigam, pelo menos, $70 \%$ de sua cobertura vegetal original, ocupam áreas superiores a $100.000 \mathrm{Km} 2$ e, desta, forma, ao considerados estratégicos no contexto das grandes mudanças globais. Apesar das ameaças à sua integridade, menos de 2\% da Caatinga está protegida como unidades de conservação e proteção integral.

A conservação da Caatinga é importante tanto para a manutenção da biodiversidade local, quanto para os padrões regionais e globais do clima, da disponibilidade de água, de solos férteis, além de promover um equilíbrio no processo do êxodo rural. Foram identificadas 82 áreas prioritárias para a conservação da caatinga, embora existam atualmente 16 unidades de conservação federais e 7 estaduais, nos estados da Bahia e do Rio Grande do Norte.

\section{A SEMI-ÁRIDEZ E A DESERTIFICAÇÃO}

O que caracteriza uma região como árida ou semi-árida não é apenas a disponibilidade de água, mas a quantidade de chuvas anuais. Sobre essas regiões, Matallo Júnior (2001, p.14) afirma que,

As regiões áridas e semi-áridas espalham-se por todos os continentes do globo, ocupando 1/3 de toda a superfície da terra e abrigando cerca de 1/6 de toda a população. Foram, conforme nos mostram estudos históricos e arqueológicos, as primeiras áreas a serem povoadas em toda a história humana e, em muitas delas, erguem-se ricos impérios e majestosas civilizações que forjaram a moderna cultura ocidental e oriental.

Durante muitos séculos as regiões secas estiveram isoladas dos processos de produção de excedentes econômicos para os mercados de alimentos e manufaturados sendo quase que exclusivamente fornecedoras de matérias primas. $\mathrm{O}$ que caracterizou o período colonial como da exploração extrativista, resultado no isolamento das populações e das 
economias vigentes que eram de subsistência, com baixos níveis de tecnologia, limitando dessa forma o seu desenvolvimento. Como resultado desse processo, obtevese uma instauração de um padrão de exploração dos recursos naturais insustentáveis face às demandas.

Matallo Júnior (2001, p.16), enaltece ainda que,

Na verdade, o principal problema das regiões secas que se materializa no processo de desertificação e se apresenta como um problema de natureza global, resulta da própria globalização do processo de produção e circulação de mercadorias, onde exigências de criação de excedente econômico pela via da produtividade se choca com os padrões tradicionais vivenciados pelas populações das terras secas e com limitações de recursos naturais, especialmente solo e água.

A nossa agricultura teve no seu desenvolvimento a dependência das tecnologias européias. Exemplo disso citam-se os casos do milho, da batata, do tomate e do feijão que, depois de descobertos nas terras secas, foram levadas para a Europa e adaptadas aos climas temperados, retornaram para as áreas secas para a "sustentabilidade" das economias coloniais.

Schenekel e Júnior (2005, p.21) a respeito da história da desertificação destacam que

O conceito de desertificação tem início nos anos 30, quando intensos processos de degradação ocorreram em alguns estados do meio oeste americano. Desmatamentos e a intensificação da exploração dos solos por meio da agricultura e pecuária, agravados por uma forte seca entre os anos 1929 e 1932, foram às causas principais do processo que ficou conhecido como Dust Bowl. Mas foi somente no início dos anos 70, quando ocorreu uma grande seca na região localizada abaixo do deserto do Sahara, onde mais de 500.000 pessoas morreram de fome, que a comunidade internacional reconheceu o impacto econômico, social e ambiental do problema estabelecendo um programa mundial de ação para combater a desertificação.

A Conferência das Nações Unidas sobre Meio ambiente e Desenvolvimento (CNUMAD) de 1992 definiu desertificação como sendo “a degradação da terra nas regiões áridas, semi-áridas e sub-úmidas secas, resultantes de vários fatores, entre eles as variações climáticas e atividades humanas", "Por degradação da terra se entende a degradação dos solos e recursos hídricos, da vegetação e biodiversidade, e a redução da qualidade de vida das populações afetadas” (MINISTÉRIO DO MEIO AMBIENTE, 1999).

Já para Araújo (2002, p.17),

O fenômeno da desertificação pode ser visto como um círculo vicioso de degradação crescente onde a erosão causa a diminuição da capacidade de retenção de água pelos solos, que leva a redução de biomassa, com menores aportes de matéria orgânica ao solo; este se torna cada vez menos capaz de reter água, a cobertura vegetal raleia e 
empobrece, a radiação solar intensa desseca ainda mais o solo e a erosão se acelera, promovendo a aridez. Trata-se de um processo de simplificação ecológica, onde a ação do homem tem tipo papel fundamental, acelerando seu desenvolvimento e agravando as conseqüências através de práticas inadequadas de uso dos recursos naturais.

Não se deve esquecer que paralelo ao processo de degradação das terras está associado o empobrecimento do solo, erosão, redução da biodiversidade e um aumento da pobreza. De acordo com Schenekel e Junior (2005, p.28), "nas áreas susceptíveis à desertificação e à seca, vivem hoje cerca de 900 milhões de pessoas e, destas, cerca de 200 milhões já estão afetadas por este processo”.

\section{DESERTIFICAÇÃO: UM PROBLEMA A SER CARACTERIZADO}

Ao abordarmos uma temática tão complexa, nos deparamos com alguns questionamentos importantes a serem estudados para que se possa ter uma melhor compreensão acerca do problema ora citado. Trata-se da questão conceitual que aponta para fragilidades teóricas metodológicas do tipo: amplitude conceitual, ausência de métodos universalmente aceitos para a identificação de processos de desertificação, falta de clareza na diferenciação entre desertificação e seca e falta uma avaliação econômica segura sobre os seus impactos ao meio ambiente e ao homem.

Para facilitar os estudos da problemática, o Instituto Desert deu uma importante contribuição para o desenvolvimento e consolidação do modo de pensar a desertificação através da estruturação de uma metodologia que é utilizada nos mais diversos países. A metodologia consta de um quadro de indicadores abordando 19 elementos, enfocando os aspectos físicos, biológicos e socioeconômicos, demonstrados no quadro abaixo: 


\section{Quadro 1: Indicadores de estudos da desertificação}

\begin{tabular}{|c|c|c|}
\hline Indicador & Definição & Presença \\
\hline 1. Densidade demográfica & $\mathrm{Hab} / \mathrm{Km}^{2}$ & $>20 \mathrm{hab} / \mathrm{Km}^{2}$ \\
\hline 2. Sistema fundiário & Índice de Gini & $>0,74$ \\
\hline 3. Mineração & Atividade no município & Presença \\
\hline 4. Qualidade da água & $\begin{array}{l}\text { Risco de salinidade S3 ou S4 } \\
\text { Risco de alcalinidade C3 ou C4 }\end{array}$ & Presença \\
\hline 5. Salinização & Presença & Presença \\
\hline 6. Tempo de ocupação & Ocupação antiga & Presença \\
\hline 7. Mecanização & 1 trator para até 470 ha & Presença \\
\hline 8. Estagnação econômica & Ver indicadores locais & Presença \\
\hline 9. Pecuarização & Ver quantidade & Presença \\
\hline 10. Erosão & Ver quantidade & Presença \\
\hline 11. Perda de fertilidade & $\begin{array}{l}\text { Redução na produção agrícola } \\
\text { ou pecuária }\end{array}$ & Presença \\
\hline 12. Área de preservação & $\begin{array}{l}\text { Existência de áreas de risco: } \\
\text { nascentes, penhascos, encostas. }\end{array}$ & Presença \\
\hline 13. Defensivos agrícolas & $\begin{array}{l}\mathrm{N}^{\mathrm{o}} \text { de estabelecimentos que } \\
\text { usam defensivos maior que } \\
45 \%\end{array}$ & Presença \\
\hline 14. Área agrícola & $\begin{array}{l}\text { Mais de } 50 \% \text { da área municipal } \\
\text { ocupada com atividades } \\
\text { agrícolas }\end{array}$ & Presença \\
\hline 15. Bovinicultura & $\begin{array}{l}\text { Presença de rebanho bovino na } \\
\text { microrregião }\end{array}$ & Presença \\
\hline 16. Caprinocultura & Presença de rebanho caprino & Presença \\
\hline 17. Ovinocultura & Presença de rebanho ovino & Presença \\
\hline 18. Evolução demográfica & $\begin{array}{l}\text { Evolução da população da } \\
\text { microrregião inferior a } 50 \% \text { da } \\
\text { evolução da população do } \\
\text { Nordeste, entre } 2 \text { censos. }\end{array}$ & Presença \\
\hline $\begin{array}{l}\text { 19. Susceptibilidade à } \\
\text { desertificação }\end{array}$ & $\begin{array}{l}\text { Quando a microrregião } \\
\text { encontra-se em área de } \\
\text { susceptibilidade. }\end{array}$ & Presença \\
\hline
\end{tabular}

Fonte: Matallo Júnior (2001, p.56)

A partir desses indicadores, buscou-se uma classificação das microrregiões da parte semi-árida e sub-úmidas do nordeste:

a) Muito grave, quando apresentam no mínimo 15 dos 19 indicadores;

b) Grave, quando apresentam entre 11 e 14 indicadores;

c) Moderada, quando apresentam entre 6 e 10 indicadores.

Desertificação no mundo

A Convenção de Combate à Desertificação, reunida em 1994, e a Agenda 21 delimitaram a problemática da desertificação já em 33\% da superfície terrestre, o 
equivalente a uma área de $51.7200 .000 \mathrm{Km}^{2}$, atingindo aproximadamente 100 países em todos os continentes habitáveis, colocando fora de produção, cerca de 6 milhões de hectares por ano, devido ao sobrepastoreio, salinização dos solos por irrigação inadequada e pelo uso intensivo e sem manejo adequado do solo pela atividade agrária.

De acordo com os estudos do IDEMA (2004, p.19):

Este processo vem colocando fora de produção, anualmente, cerca de 6 milhões de hectares e as perdas econômicas anuais giram em torno de 1 bilhão de dólares e o custo de recuperação das terras em todo o mundo pode chegar a 2 bilhões de dólares por ano.

A África é a região mais afetada, merecendo também preocupação a China e outras áreas onde o problema também é muito presente, o Oeste da América do Sul, o Nordeste do Brasil, o Oriente Médio, a Austrália e o Sudeste dos Estados Unidos.

\section{Desertificação no Brasil}

O início dos estudos sobre a desertificação no Brasil remonta na década de 1970 (BRASIL, 2004, p. 33), tendo sido o prof. Vasconcelos Sobrinho o pioneiro na indicação de núcleos de desertificação no Brasil (VASCONCELOS SOBRINHO, 1971). Em 1977, por ocasião da Conferência Internacional das Nações Unidas para o Combate à Desertificação - UNCOD, a desertificação tornou-se tema de debate mundial. Reconhecida como Conferência de Nairobi, sua principal finalidade seria a de traçar o Plano de Ação Mundial para Combater a Desertificação - PACD (NIMER, 1988). Porém, nos 15 anos que separaram a Conferência de Nairobi da Conferência Internacional das Nações Unidas sobre o Meio Ambiente - RIO 92, poucos eventos ocorreram ou ações se desenvolveram, mundialmente, no sentido de combater ou controlar a desertificação.

O Brasil possui grande parte do seu território localizado em região semi-árida, estando, assim, sujeito ao fenômeno da desertificação. Segundo dados apontados pelo Projeto PNUD/BRA/93/036, o Nordeste do país já apresenta cerca de $180.000 \mathrm{Km}^{2}$ de áreas com processos de degradação considerados como muito grave e grave, sendo que $18.740 \mathrm{Km}^{2}$ apresentam sinais intensos muito preocupantes - os chamados núcleos de desertificação - localizados em Gilbués/PI, Irauçuba/CE, Cabroró/PE e na região do Seridó do RN (BRASIL, 2005).

\section{A DESERTIFICAÇÃO NO RIO GRANDE DO NORTE}

\section{RIO GRANDE DO NORTE: ASPECTOS EDOFO-CLIMÁTICOS}

No Rio Grande do Norte, as transformações ocorridas na economia mundial e no Brasil trouxeram conseqüências profundas de natureza econômica, social e ambiental. A crise energética que afetou a indústria petrolífera levou à realização de pesquisas, resultando em novas descobertas de um potencial de produção, transformando o estado, o segundo produtor nacional. A abertura da economia brasileira possibilitou a diversificação, no Rio Grande do Norte, das atividades industriais, agroindustriais e de serviços, 
merecendo destaque a indústria têxtil, a fruticultura irrigada e o turismo. Isso tudo fez com que esse estado tivesse uma taxa de desenvolvimento bem mais elevada que os demais da região. Porém, tudo isso não foi o suficiente para resolver os problemas das desigualdades e da exclusão social nas cidades e no campo.

O Rio Grande do Norte possui um área de 53.306,8 $\mathrm{Km}^{2}$, representando 0,62\% do território nacional, com uma população de 2,6 milhões de habitantes, sendo $72 \%$ em área urbana e $28 \%$ em áreas rurais. Por possuir a maior parte de sua área enquadrada no semi-árido, tem uma representatividade muito grande na problemática ambiental da desertificação. O seu território esta incluído nas categorias muito grave e grave de ocorrência de desertificação, observando-se processos de degradação ambiental de importância considerável. Essas ocorrências estão situadas na Microrregião homogênea do Seridó, Salineira Norte-rio-grandense, Assu-Apodi, Serra Verde e Microrregião homogênea serrana norte-rio-grandense.

Nessas áreas, identificam-se atividades de alto potencial de degradação, tais como a mineração, a agropecuária tradicional e o extrativismo vegetal, que causam sérios problemas de erosão e seus conseqüentes impactos sobre os recursos hídricos existentes. Por outro lado, nos perímetros irrigados já são detectados significativos impactos causados pelo uso excessivo de mecanização e de defensivos agrícolas em grandes quantidades, além da salinização dos solos devido ao emprego de técnicas inadequadas de irrigação e drenagem.

O Seridó do Rio Grande do Norte tem sido objeto de múltiplas regionalizações fundamentadas em critérios de natureza espacial, econômica e a administrativa, as quais levaram à formação de territórios artificiais e fronteiras político-administrativas diferenciadas.

A economia, o desenvolvimento social e político foram estruturados a partir de duas matrizes básicas: a pecuária, algodão e produtos alimentícios juntamente com a atividade de extração mineral. Esse processo todo de transformação econômica e social da região trouxe como conseqüência um grande avanço no processo de degradação ambiental. As atividades de pecuária e produção agrícola contribuíram para o processo de desmatamento da área e para o empobrecimento do solo. A atividade de mineração (praticamente extinta) provocou impactos ambientais irreparáveis e até hoje visíveis. A indústria de cerâmica vermelha conforme descrito pelo Projeto PNUD/FAO/IBAMA, utiliza a lenha como combustível para a queima dos produtos em fornos intermitentes. Segundo Bando do Nordeste (2008, p. 200), o processo de produção empregado ainda é o mesmo do século passado, e as raras inovações tecnológicas objetivam apenas a automação do processo, visando reduzir os custos de mão-de-obra. Todos esses processos têm transformado o Seridó potiguar em uma região com sérios problemas ambientais.

A desertificação, como já fora conceituada anteriormente, é provocada por fatores físico-climáticos e antrópicos: desmatamentos, queimadas, técnicas inadequadas de irrigação, sobrepastoreios, mineração, uso intensivo e inadequado do solo na agricultura e pressão populacional. De acordo com a Secretaria de Ciência e Tecnologia e Meio Ambiente do Estado do Pernambuco (SECTMA, 1999), a ação combinada desses fatores naturais e antrópicos resulta em problemas do tipo: 
- Ambiental - erosão e salinização dos solos, perda da biodiversidade, diminuição da disponibilidade e da qualidade dos recursos hídricos, entre outros;

- Social - principalmente desestruturação familiar pela necessidade de emigrar para centros urbanos devido à perda da capacidade produtiva da terra. Com isso, criam-se novas demandas sociais que exploram a capacidade do Estado em atendê-las;

- Econômica - destacam-se na produtividade e produção agrícolas (sobretudo na agricultura de sequeiro que é mais vulnerável aos fatores climáticos), e a diminuição de renda do consumo da população. Além disso, a perda da capacidade produtiva da sociedade repercute diretamente na arrecadação de impostos e na circulação de renda.

De acordo com o IDEMA (1999, p. 14), o Rio Grande do Norte possui 95\% de sua área enquadrada nos climas árido, semi-árido e sub-úmido seco, podendo ser considerado como bastante representativo dessa problemática ambiental. Com 63\% de seu território incluído nas categorias Muito Grave e Grave de ocorrência de desertificação devido a atividades antrópicas supracitadas. No estado, segundo este mesmo órgão, podem ser encontrados diversos tipos de climas, como:

- Árido, localizado na parte central e litoral setentrional e abrange $18 \%$ da superfície estadual;

- Semi-árido, domina, de forma quase contínua, todo o interior do Estado, perfazendo uma área de $57 \%$ da superfície estadual;

- Sub-úmido seco, abrange $20 \%$ da superfície estadual, localizando-se em parte, no litoral oriental e nas áreas serranas do interior do estado;

- Úmido, localizado no litoral oriental, representando 5\% da área estadual.

O Rio Grande do Norte está situado em uma área de vegetação constituída principalmente por plantas xerófilas (Plantas adaptadas ao clima seco)a qual está passando por um processo significativo de redução. De acordo com o IBAMA (1992), no estado podem ser encontrados dois tipos de caatinga: a hiperxerófila, representando $60 \%$ da área ocupada e a hipoxerófila, com 20\%. Em 1988, a caatinga ocupava 52\% da superfície do Estado, hoje restam apenas 56\% em condições de exploração sustentada.

Dados do Instituto de Pesquisa Econômica Aplicada (IPEA, 1998) apontam para uma gravidade muito grande no bioma. O quadro abaixo nos mostra a realidade de impactos sobre a vegetação.

\section{Quadro 2: Caracterização da desertificação no Rio Grande do Norte}

\begin{tabular}{|l|c|c|c|c|}
\hline \multicolumn{1}{|c|}{$\begin{array}{c}\text { Classe da } \\
\text { intensidade }\end{array}$} & Área Km ${ }^{2}$ & Área \% & $\begin{array}{c}\text { População em } \\
\text { números }\end{array}$ & População\% \\
\hline Muito Grave & 12.965 & 24,3 & 289,767 & 11, \\
\hline Grave & 20.545 & 38,5 & 591,158 & 22,5 \\
\hline Moderada & 5.120 & 9,6 & 215,112 & 8,2 \\
\hline $\begin{array}{l}\text { Total Afetado } \\
\text { RN }\end{array}$ & 38.630 & 72,5 & 1.096 .037 & 41,7 \\
\hline Estado & 53.307 & 100,0 & 2.630 .000 & 100,00 \\
\hline
\end{tabular}

Fonte: (IPEA, 1998) 
Como se observa no quadro acima, a questão do desmatamento da vegetação é um dos fatores de extrema gravidade no processo de desertificação. Ao desmatar, o solo fica desnudo e sofre processo de erosão e perda de nutriente, reduzindo assim a sua fertilidade.

Um estudo publicado pelo IDEMA (2004) "Diretrizes para política de controle da desertificação no Rio Grande do Norte” é possível encontrar uma classificação e caracterização das áreas de desertificação no Rio Grande do Norte, que será descrito a seguir:

- Muito grave: Microrregião homogênea do Seridó - corresponde a uma área de $24,3 \%$ da superfície territorial do estado e abriga $11 \%$ de sua população, distribuída em 28 municípios. O elevado grau de urbanização (68\%) observado na região é fortemente influenciado pelas cidades de Caicó, Currais Novos e Parelhas, onde as taxas de urbanização são superiores a 80\%. Essa área ainda é classificada como de baixo desenvolvimento. A microrregião possui um clima muito quente e semi-árido, tipo estepe, os solos de modo geral são compostos de rochas cristalinas e granitos. Os cursos de água são intermitentes, pois suas áreas de drenagem quase sempre ocorrem sobre embasamentos cristalinos, cujos solos são rasos e pedregosos. "Os principais ramos consumidores de energéticos florestais são a industria cerâmica, as padarias e as olarias, que, juntas, consumiam, em 1989, 79.500st/ano, isto é, mais da metade de todo o consumo industria”. (ZAKIA et al, 1990 apud IDEMA, 2004, p.21). Estudos do IDEMA (2000, p.12) mostram que, das 77 cerâmicas em atividade naquela região, 53 (69\%) estão distribuídas em 4 municípios: Parelhas, Carnaúba dos Dantas, Jardim do Seridó e Acari, porém a desertificação já atinge também os municípios de Cruzeta, Equador e Currais Novos que fazem parte do Programa Nacional de Combate à desertificação (PNCD).

- Grave: Microrregiões Salineiras Norte-rio-grandenses, Assú e Serra Verde, essa região representa 38,5\% do território estadual e engloba 33 municípios. A população dessa região é de 591.158 habitantes, correspondendo a $22 \%$ do estado. A população economicamente ativa (PEA), da região depende, em sua maioria dos setores primário e terciário. Quanto aos aspectos físicos, possui uma faixa litorânea com relevo plano, e com sedimentos na orla marítima que formam as praias, dunas, mangues, várzeas e terraços fluviais. Os solos são arenosos, solos aluviais e solos orgânicos. Essa área é ocupada ainda pelos vales dos Rios Piranhas (Assú) e Apodi.

- Moderado: Microrregião Homogênea Serrana Norte-rio-grandense - possui uma área de $5.120 \mathrm{Km}^{2}$, correspondendo a cerca de $10 \%$ do território estadual, e abrange 36 municípios, onde vivem 215.112 pessoas, sendo 60\% delas nas cidades. A região é caracterizada pelo predomínio forte-ondulado e montanhoso, com inclusões de partes com topografia suave ondulada e plana. O relevo é constituído por encostas de serras (altitudes de 350 a $750 \mathrm{~m}$ ) ou conjunto de morros com fortes declividades e erosão acentuada. O clima é tipicamente úmido, solos profundos e bem drenados. A economia é baseada em atividades agropecuárias, extração vegetal e pesca.

Entre todas as microrregiões castigadas pelo processo da desertificação, percebe-se uma relação muito próxima com a atividade econômica vigente na área. Em algumas áreas como a do Seridó, além de atividade de mineração para retirada do granito e areia, 
existe uma intensa atividade que é a retirada de lenha para as cerâmicas de região. A tabela 3 exibe a realidade citada.

Quadro 3: Balanço de pessoal, consumo de lenhas e argila, e de produção, por região (mensal).

\begin{tabular}{|l|c|c|c|c|c|c|c|c|}
\hline Região & Pessoal & $\begin{array}{c}\text { Lenha } \\
\left(\mathbf{m}^{\mathbf{3}}\right)\end{array}$ & $\begin{array}{c}\text { Argila } \\
\mathbf{( t )}\end{array}$ & $\begin{array}{c}\text { Telhas } \\
\mathbf{( x 1 0 0 0})\end{array}$ & $\begin{array}{c}\text { Tijolos } \\
(\mathbf{x 1 0 0 0})\end{array}$ & $\begin{array}{c}\text { Lajotas } \\
(\mathbf{x 1 0 0 0})\end{array}$ & $\begin{array}{c}\text { Outros } \\
(\mathbf{x 1 0 0 0})\end{array}$ & $\begin{array}{c}\text { Total } \\
(\mathbf{x 1 0 0 0})\end{array}$ \\
\hline $\begin{array}{l}\text { Bacia do } \\
\text { Seridó }\end{array}$ & 2.612 & 34.649 & 63.834 & 37.998 & 1.230 & 99 & - & 39.327 \\
\hline Baixo Açu & 1.331 & 31.719 & 44.367 & 9.830 & 7.067 & 1.626 & - & 18.523 \\
\hline $\begin{array}{l}\text { Bacia do } \\
\text { Potengi }\end{array}$ & 682 & 17.977 & 35.277 & - & 12.887 & 786 & - & 13.673 \\
\hline $\begin{array}{l}\text { Bacia do } \\
\text { Trairi/Jacu }\end{array}$ & 401 & 9.246 & 14.069 & 1.224 & 3.366 & 210 & 432 & 5.232 \\
\hline $\begin{array}{l}\text { Bacia do } \\
\text { Apodi }\end{array}$ & 279 & 7.463 & 8.592 & 1.000 & 2.342 & 40 & - & 3.382 \\
\hline $\begin{array}{l}\text { Zona Centro } \\
\text { e Serrana }\end{array}$ & 121 & 3.272 & 4.682 & 120 & 1.510 & 70 & - & 1.700 \\
\hline $\begin{array}{l}\text { Bacia do } \\
\text { Ceará-Mirim }\end{array}$ & 56 & 1.371 & 1.524 & - & 762 & - & - & 762 \\
\hline $\begin{array}{l}\text { Bacia do } \\
\text { Curimataú }\end{array}$ & 12 & 800 & 580 & - & 200 & - & - & 200 \\
\hline RN & 5.494 & 106.497 & 173.925 & 50.172 & 29.364 & 2.831 & 432 & 82.799 \\
\hline
\end{tabular}

FONTE: (FIERN/SENAI, 2001, p. 26)

Assim sendo, é importante destacar que a região do Seridó potiguar é uma área que tem apresentado uma vulnerabilidade muito grande quando o item é a desertificação. Seja por fatores naturais como a semi-aridez, alta incidência de luz solar, chuvas torrenciais e erosão, seja por fatores antrópicos já correlacionados. Os impactos desse processo já estão bem visíveis nos meios ambientais, econômicos e sociais da região. Contudo, é importante deixar claro que a região não é apenas uma área de fragilidade, pelo contrário, possui potencialidades que, se exploradas racionalmente, poderão mudar a realidade socioambiental local.

\section{CONCLUSÃO}

Ao se abordar a problemática do Nordeste brasileiro, é comum nos depararmos com uma imensidão de olhares heterogêneos sobre a região, mas, entre todos os diferentes olhares, o que tem perdurado é o do atraso e da miséria. Essa realidade tem sido mudada de forma gradativa e a partir de investimentos nas mais diversas áreas, principalmente nas áreas de educação, saúde e economia. Olhar o sertão do Nordeste hoje não é ver um mundo onde a eqüidade social é o elemento de referência. Porém, percebemos que muita coisa mudou na região se usarmos como parâmetro algumas décadas do passado.

A desertificação, a longo dos últimos tempos, tem causado uma diminuição drástica das terras férteis, o que, aliado ao aumento da demanda por alimentos, tem contribuído para aumentar a fome e desencadear importantes fluxos migratórios do campo para as cidades. Para minimizar esse processo destruidor é necessário conter o avanço desse processo de desertificação com medidas sociais e tecnológicas por todos os segmentos sociais dessa área territorial, envolvendo não somente os agentes governamentais, mas sobretudo toda a sociedade civil e organizada. A saída pode estar no desenvolvimento 
sustentável que se baseia na durabilidade do crescimento econômico, conservação da natureza e eqüidade social. A sustentabilidade dos recursos naturais implica limitações definidas nas possibilidades de crescimento econômico. É necessária a criação de regras que possam ser eficientes na gestão dos recursos naturais para que o homem e a natureza possam interagir de forma prudente.

É preciso ter em mente que a desertificação é uma forma crescente de miserabilidade de uma área espacial e que, se não forem tomadas medidas urgentes, parte significativa da população do estado poderá perder definitivamente os seus meios de produção e sobrevivência, o que trará como efeito um inchaço das cidades mais desenvolvidas e, conseqüentemente, um crescimento das favelas. A sustentabilidade consiste em encontrar meios de produção, distribuição e consumo de recursos existentes de forma mais coesiva, economicamente eficaz e ecologicamente viável.

\section{REFERENNCIAS}

ARAÚJO, Alexandre José do Rego Pereira et al. Desertificação e seca: contribuição da ciência e tecnologia para a sustentabilidade do semi-árido do Nordeste do Brasil. Recife: Nordeste, 2002.

BANCO DO NORDESTE. Manual de impactos ambientais: orientações básicas sobre aspectos ambientais de atividades produtivas. Fortaleza: Banco do Nordeste, 2008.

BEZERRA, M. C. L.; BURSZTYN, M. (cood.). Ciência e Tecnologia para o desenvolvimento sustentável. Brasília: Ministério do Meio Ambiente e dos Recursos Naturais Renováveis: Consórcio CDS/ UNB/ Abipti, 2000.

BRANCO, Samuel Murgel. Caatinga: a paisagem do homem sertanejo. São Paulo: Moderna, 1998.

BRASIL. Ministério do Meio Ambiente dos Recursos Hídricos e da Amazônia Legal. Desertificação: caracterização e impactos. 8f. (PROJETO PNUB/BRA/93-36).

BRASIL. Ministério do Meio Ambiente. Programa de ação nacional de combate à desertificação. Brasília, 2005.

BURSZTN, M. Para pensar o desenvolvimento sustentável. São Paulo: Brasiliense, 1994.

CAVALCANTI, Agostinho Paula Brito. Desenvolvimento sustentável e planejamento: bases teóricas e conceituais. Fortaleza: UFC - Imprensa Universitária, 1997.

CAVALCANTI, Clóvis. (org.). Desenvolvimento e Natureza: estudos para uma sociedade sustentável. São Paulo: Cortez, 2003.

CONFERÊNCIA DAS NAÇÕES UNIDAS SOBRE MEIO AMBIENTE E DESENVOLVIMENTO. Agenda 21. Rio de Janeiro, 1992. 
DONAIRE, D. Gestão Ambiental na Empresa. São Paulo: Atlas, 1995.

DUQUE, José Guimarães. Solo e água no polígono das secas. 5. ed. Mossoró: Coleção Mossoroense, 1980.

FEDERAÇÃO DAS INDÚSTRIAS DO RIO GRANDE DO NORTE. Perfil Industrial da cerâmica vermelha no $\mathbf{R N}$. Disponível em:<www.ctgas.com.br $>$. Acesso em: 12 dez. 2004.

INSTITUTO BRASILEIRO DO MEIO AMBIENTE E DA AMZÔNIA LEGAL. Plano de manejo florestal para a Região do Seridó do Rio Grande do Norte. V.1, Natal, 1992.

IDEMA. Anuário Estatístico do Rio Grande do Norte. Natal, v.26, 1999.

Diretrizes para política de controle da desertificação no Rio Grande do Norte. Natal, 2004.

IPEA. Atlas de Desenvolvimento Humano no Brasil. Brasília, 1998.

MATALLO JÚNIOR, Heitor. Indicadores de desertificação: histórico e perspectivas. Brasília: UNESCO, 2001.

PERNAMBUCO. Secretaria de Ciência Tecnologia e Meio Ambiente. Política Estadual de Controle da Desertificação. Recife, 2000.

PERUEL, Rodolfo. (Org). Brasil: descentralizacion y el desarrolo municipal sustentable - la experiencia del Seridó Potigual.Natal: Gobierno del Estado, 2001.

SACHS, Ignacy. Ecodesenvolvimento, Creser sem Destruir. São Paulo: Vértice. 1986.

SCHENEKEL, Hans George; MATALLO JUNIOR, Heitor. A desertificação. Disponível em: <www.ecoambiental.com.br>. Acesso em: 17 set. 2005.

TABARELLI, Marcelo; LEAL, Inara; SILVA, José Maria. Ecologia e conservação da caatinga. Recife: UFPE, 2004. 